\title{
Search for Cyclotron Resonance in Cells In Vitro
}

\author{
W.C. Parkinson and C.T. Hanks \\ Department of Physics (W.C.P.) and School of Dentistry (C.T.H.), University of Michigan, \\ Ann Arbor
}

\begin{abstract}
There are a number of reports of the plasma membrane transport of $\mathrm{Ca}^{2+}$ in biological systems being enhanced by low frequency electromagnetic fields (EMF), including reports that the enhancement involves a resonance-type response at the cyclotron frequency for $\mathrm{Ca}^{2+}$ ions for geomagnetic values of the magnetic field. Using the fluorescent probe fura2, we find no evidence for changes in cytosolic calcium concentration in BALB/c3T3, L929, $\mathrm{V}-79$, and ROS, a rat osteosarcoma cell line, at the application of both resonant and nonresonant EMF.
\end{abstract}

Key words: EMF, fura2, Ca transport

\section{INTRODUCTION}

There are now many published reports of the interaction of electromagnetic fields (EMF) with a variety of biological systems. Of particular interest here are those that reported the interaction to exhibit a "window" effect, a resonance-type response of the frequency and amplitude of the EMF. Conti et al. [1983] reported an inhibitory effect of the EMF on blastogenesis of mitogen-stimulated human lymphocytes, the inhibitory effect showing a "window" dependence on frequency $(3-50 \mathrm{~Hz})$. They suggested that an alteration of calcium fluxes by the EMF may be the most realistic hypothesis to explain their observed effect. Delgado et al. [1982] reported that a pulsed EMF of $100 \mathrm{~Hz}$ and $1.2 \mu \mathrm{T}$ intensity had a powerful inhibitory effect on chicken embryogenesis. A "window" effect was also observed: embryos exposed to fields of $100 \mathrm{~Hz}, 1.2 \mu \mathrm{T}$, were less developed than embryos exposed at lower and higher intensities and frequencies.

Bawin and Adey [1976] have reported that weak sinusoidal electric fields modify the calcium efflux from freshly isolated chick and cat cerebral tissue. Both frequency and amplitude windows were observed for the selective inhibition of calcium release from cerebral tissue, with maximum tissue sensitivity in the frequency region of 6 and $16 \mathrm{~Hz}$ and an amplitude between 56 and $100 \mathrm{~V} / \mathrm{m}$. On the other hand, a comparable increase occurs from isolated chick cerebral tissue exposed

Received for review April 7, 1988; revision received July 22, 1988.

Address reprint requests to W.C. Parkinson, Department of Physics, University of Michigan, Ann Arbor, MI 48109.

(C) 1989 Alan R. Liss, Inc. 
to radiofrequency fields that are amplitude modulated at frequencies between 6 and $25 \mathrm{~Hz}$ [Bawin et al., 1975].

Blackman et al. [1982] reported an enhancement in calcium-ion efflux from isolated chick brains at specific ranges of low frequency fields: $16-\mathrm{Hz}$ fields were effective but 1-, 30-, and 32-Hz fields were not. While Blackman et al. [1982] reported an enhancement in calcium-ion efflux, Bawin and Adey [1976] reported a reduction. It was suggested [Blackman et al., 1985] that the difference was due to the fact that Bawin and Adey used an oscillating (AC) electric field, while Blackman et al. used an alternating current $(\mathrm{AC})$ electromagnetic field. In testing this hypothesis they demonstrated the importance of the $\mathrm{AC}$ magnetic component of the field, and indeed the importance of the local geomagnetic field. As an alternative hypothesis, Blackman et al. [1982] suggested that the "cause may be found in slightly different preparations and procedures used in the two laboratories."

The "window" effect led to the hypothesis of "cyclotron resonance" first mentioned by Blackman at the 1984 BEMS meeting in Atlanta (personal communication) and by Blackman [1985], Liboff [1985], and Chiabrera et al. [1985]. Chiabrera et al. considered that the field acts on the binding process of a ligand to its binding site, a process occurring on the membrane surface or the glycocalyx. The concept that this extended membrane region (the glycocalyx) surrounding the neural membrane may be sensitive to electric fields was first proposed by Adey [1974]. Liboff [1985], on the other hand, suggested that it is the transport of calcium ions through channels spanning the cell membrane that involves a resonance-type response to the applied EMF. While both Bawin and Adey [1975, 1976] and Blackman et al. [1982] spoke of calcium efflux, their results could be interpreted as efflux from the glycocalyx or from the cell membrane, or efflux due to calcium transport from the cytosol. In support of the Liboff concept, McLeod et al. [1987] reported that it is the transport of calcium ions across the cell membrane that involves the resonance-type response, and they demonstrated that the $\mathrm{Ca}^{2+}$-dependent motility of diatoms was enhanced at the calcium-ion cyclotron resonance frequency. The resonance is reported to occur in direct current (DC) magnetic fields of the order of the geomagnetic field and in $\mathrm{AC}$ fields of the same magnitude and of frequency corresponding to the cyclotron frequency for calcium ions in free space $\left(\omega_{c}=B \mathrm{q} / \mathrm{m}\right.$, where $\mathrm{q} / \mathrm{m}$ is the charge-to-mass ratio of the calcium ion and $B$ is the value of the magnetic field). It should be noted that the electric field intensity used by Bawin and by Blackman was substantially different than that of McLeod et al. [1987] and Smith et al. [1987].

Rasmussen and Barrett [1984], in their extensive review of the calcium messenger system, suggest that the plasma membrane plays the predominant role in maintaining cellular $\mathrm{Ca}^{2}+$ homeostasis, and has a vital function in stimulus-response coupling when the cell employs the $\mathrm{Ca}^{2+}$ messenger system. While $\mathrm{Ca}^{2+}$ is bound to the inner surface of the membrane, considerably more is bound to the glycocalyx. On activation of a cell by a particular extracellular messenger, specific channels may open in either a transient or a sustained fashion to allow $\mathrm{Ca}^{2+}$ to enter the cell down its steep concentration gradient. The channels may include a potential operated channel (POC) or voltage-dependent type, a receptor-operated channel (ROC), and in addition some $\mathrm{Ca}^{2+}$ may enter via the $\mathrm{Na}^{+}$channel. When the POC are ROC are opened by agents that induce a sustained cellular response, they remain open as long as the agent is present and the response continues. 
If indeed a resonance response occurs in the calcium transport, then changes in the cytosolic $\mathrm{Ca}^{2+}$ concentration should be detectable by means of fluorescence spectroscopy of cells loaded with a fluorescent chelating agent. The $\mathrm{Ca}^{2+}$ ions may enter (or leave) the cytosol through the cell membrane or from calcium-containing organelles within the cell.

The fluorescent probe fura2, as developed by Tsien and colleagues [Grynkiewicz et al., 1985], is a particularly sensitive probe for measuring intracellular calcium concentration, or, as in this experiment, detecting changes in the cytosolic calcium concentration. Fura 2 is a fluorescent calcium chelating agent that is transported across the cell plasma membrane as the acetoxymethyl ester (fura2AM). Fura2AM when "loaded" into the cell is hydrolyzed to the fura2 acid form, fura-2, which chelates calcium with higher affinity than $\mathrm{Mg}^{2+}$ [Grynkiewicz et al., 1985]. As the acid chelates cytoplasmic free $\mathrm{Ca}^{2+}$, the absorbance shifts from 380 to $340 \mathrm{~nm}$ while maintaining fluorescence at $500 \mathrm{~nm}$ [Tsien et al., 1985]. Thus, a change in the fluorescent intensity ratio (340:380) indicates a change in the amount of intracellular calcium bound to fura 2 . Fura- 2 remains in the cytoplasm, with a slow "leakage" rate probably due to exocytosis, unless the cell begins to undergo degeneration or is fixed (e.g., with formalin), so that the plasma membrane becomes permeable. The loading concentration of fura2AM is $3 \mu \mathrm{M}$ [in $\mathrm{Ca}^{2+}$-free incubating solution: Hallam et al., 1984]. Fura 2 has replaced another long-used fluorescent chelating agent, Quin-2, over which it has many advantages including greater fluorescent intensity for a given molarity and greater discriminating power for $\mathrm{Ca}^{2+}$ in comparison to other divalent cations [Tsien et al., 1985].

We report here on the results of searches for changes in intracellular $\mathrm{Ca}^{2+}$ concentration due to the application of both resonant and nonresonant electromagnetic fields to BALB/c3T3, L929, ROS (rat osteosarcoma), and V-79 cells. These cell types were being routinely cultured in the laboratory of one of the authors (C.T.H.). It had been found in earlier studies that one of the cell lines (ROS), but not the others, responded by galvanotropism to a DC electric field [Parkinson and Hanks, 1986]. Consequently, we were interested to determine if the EMF might influence cell behavior by modifying the transport or release of $\mathrm{Ca}^{2+}$ into the cytosol.

\section{MATERIALS AND METHODS}

\section{Experimental Arrangement: Hardware and System Configurations}

Early measurements were made with an Aminco-Bowman Model 4-8202 spectrofluorometer and a polystyrene cuvette $(1 \times 1 \times 4.7 \mathrm{~cm}$, No. 67,754, Sarstedt, Inc., Princeton, NJ) which was mounted in a plastic temperature-controlled water jacket, with the temperature maintained at $37^{\circ} \mathrm{C}$. A rectangular $(1.25 \times 3.8$ $\mathrm{cm}$ ) \#2 coverslip densely plated with cells fit diagonally into the cuvette. Two pairs of Helmholtz-like coils were placed around the cuvette with their axes colinear and in the direction of the horizontal component of the geomagnetic field. One pair provided the DC magnetic field and the other the AC field. The cuvette was filled with a calcium-free bicarbonate-buffered balanced salt solution [Tang and Weinberg, 1986] onto which $5 \% \mathrm{CO}_{2}$ in air was blown to maintain the desired $\mathrm{pH}$ level. While no effect of the EMF on $\mathrm{Ca}^{2+}$ transport was observed, the small volume of the sample chamber and the required manual setting of the excitation wavelengths made it difficult to quantify the results. 


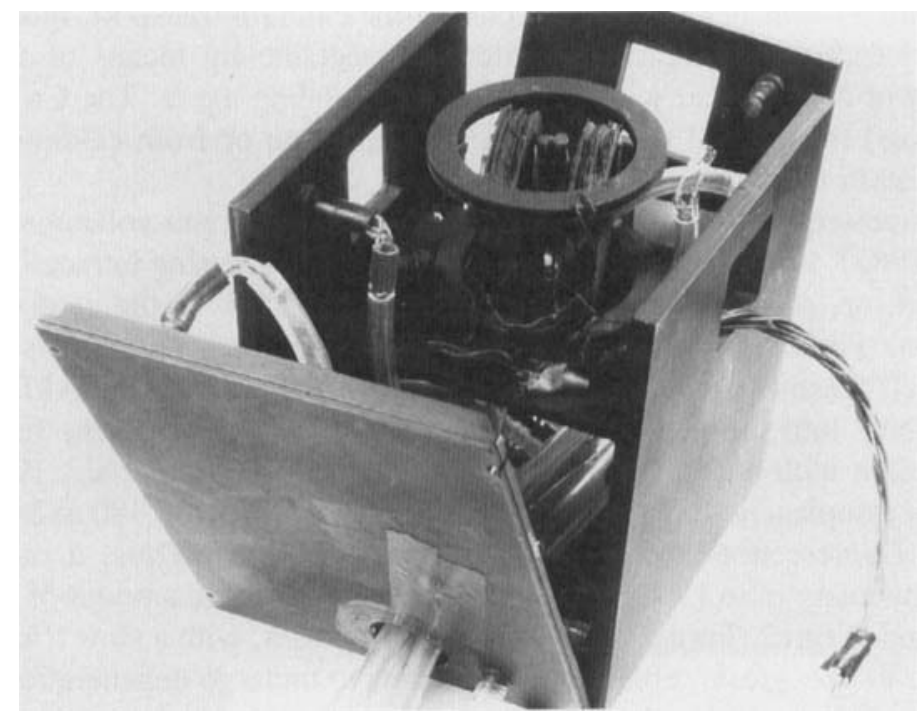

Fig. 1. Exploded view of heating panels, Helmholtz-like coils, and sample holder. The assembled unit fits snugly in the sample volume of the SLM $8000 \mathrm{C}$ spectrofluorometer. Water is circulated through the panels to maintain a constant temperature within the entire volume.

More recently, an SLM-8000C spectrofluorometer with computer controls of emission and excitation wavelengths became available (SLM Instruments, Inc., Urbana, IL). It offers the particular advantages of a large sample chamber and the ability to rapidly switch excitation wavelengths. The sample chamber volume $(6 \times$ $63 / 4 \times 73 / 4$ in.) permitted all six walls of the chamber to be covered with 3/8-in.-thick plastic panels through which water was circulated for temperature control. The panels were made by routing a channel in a 1/4-in.-thick lucite plate and cementing a $1 / 8$ in. skin over the plate (Fig. 1). Water from a styrofoam reservoir containing approximately $3 \times 10^{-3} \mathrm{~m}^{3}$ of water was circulated through the panels by a pump (Model M-40; Simer Pump Co., Minneapolis). The water temperature was maintained by a heater (Supreme Heetmaster thermostatic aquarium heater, E.G. Danner Manufacturing, Inc., Central Islip, NY) driven by a proportional temperature controller (Model 72; Yellow Springs Instrument Co., Yellow Springs, OH). The sensing element for the controller was mounted on the cuvette holder. The temperature was measured by a calibrated thermister also mounted on the cuvette holder, and for all measurements except where noted was held at $37^{\circ} \mathrm{C} \pm 0.2{ }^{\circ} \mathrm{C}$. Temperature transients occurred when the sample chamber cover was removed briefly to add reagents to the cuvette, but because of the thermal capacity of the system, and the fact that any liquid added to the cuvette was preheated to $37^{\circ} \mathrm{C}$, the transients died out in a short time, usually less than $1 \mathrm{~min}$.

The sample holder with the three pairs of coils removed is shown in Figure 2. The cells were plated on \# 1 glass coverslips cut to $3.8 \times 1.25 \mathrm{~cm}$. The coverslip was mounted diagonally in the square polystyrene cuvette and held in place by the slotted rubber stopper at the top and a slotted teflon piece at the bottom. The coverslip could be removed and then replaced in the same position. (A magnetic stirrer, because of its magnetic field, was not used.) 


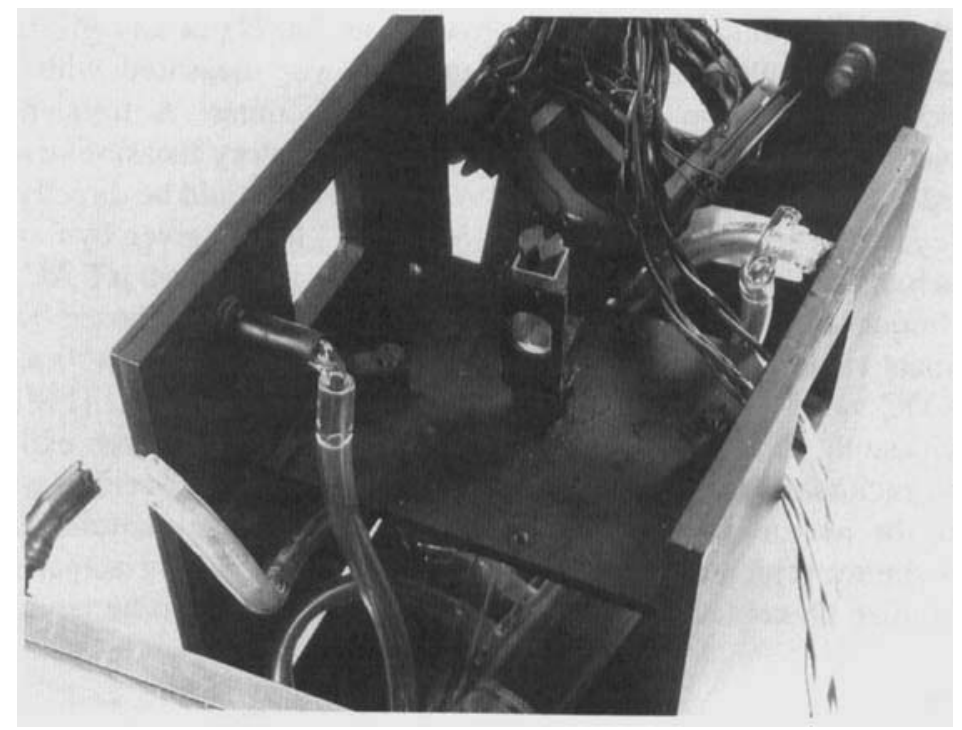

Fig. 2. Exploded view with the coils removed to expose the sample holder. The \#1 coverslip with plated cells is mounted diagonally in the square plastic cuvette. The cuvette holder can be rotated about a vertical axis to minimize reflection.

Of the three pairs of coils (Fig. 1), one pair, with its axis vertical, was used to buck-out the vertical component of the geomagnetic field. The second pair was used to set the DC horizontal component of the field to the desired value, and the third pair was used to apply the desired amplitude and frequency of the AC EMF. The axes of the DC and AC field coils were colinear, horizontal, and parallel to the horizontal component of the geomagnetic field. The coils were wound on lucite forms, the two pairs for the horizontal fields being 3 in. o.d. and $21 / 2$ in. i.d. and $1 / 4$ in. thick (1/4-in. ${ }^{2}$ winding window) and wound with 30 turns of \#22 magnet wire on each form (60 turns total on each pair). The mean spacings were 1 and $13 / 8$ in. Each pair for the vertical axis was wound on lucite forms $31 / 2$ in. o.d. $\times 3$ in. i.d. and 1/4 in. thick (1/4-in. ${ }^{2}$ window) with 16 turns of \#22 magnet wire on each. The mean separation was $21 / 4$ in.

The constant currents for the DC magnetic fields were supplied by Hewlett Packard 6216A (Berkeley Heights, NJ) power supplies and the currents monitored by Keithley Model 169 (Cleveland, OH) multimeters. The magnetic fields, both DC and AC, were measured with a Bell Model 640 (Orlando, FL) gaussmeter which uses a Hall probe sensor. The fields were uniform to $1 \%$ over the volume of the active portion of the sample. At the physical location of the sample chamber, the east-west component of the geomagnetic field was less than $0.002 \mathrm{G}$ and was ignored. The gaussmeter is sensitive not only to DC fields, but also to AC magnetic fields up to a frequency of $5 \mathrm{kHz}$ (upper-half-power point of the response). The $\mathrm{AC}$ field current was supplied by a power amplifier (Opamp Labs, Inc., Model M-150 (Los Angeles, CA)) driven by a Donner Model 1500 (Concord, CA) low frequency sinewave generator and monitored with a Keithley Model 169 (Cleveland, OH) multimeter. The output of the amplifier was coupled to the coils through a large capacitor $(6000$ $\mu \mathrm{F})$ to block DC currents. The frequency could be varied by hand or swept 
automatically and continuously (ramped) from 1 to $100 \mathrm{~Hz}$ at any given rate by a specially constructed motor drive. The frequency was measured with a Hewlett Packard model 5243L (Palo Alto, CA) electronic counter. A frequency to DC voltage converter was constructed and used in the exploratory measurements to drive a chart recorder so that fluorescent intensity vs. frequency could be directly recorded.

The "cyclotron-resonance" condition for ${ }^{40} \mathrm{Ca}^{2+}$ ions is given by $\mathrm{f}=7,630 \times$ $\mathrm{B}(\mu \mathrm{T})$. Much of the data were taken with $\mathrm{B}=50 \mu \mathrm{T}$ DC and $50 \mu \mathrm{T}$ AC amplitude (peak) at a frequency of $38.15 \mathrm{~Hz}$. The value $50 \mu \mathrm{T}$ (DC) was chosen because it is the approximate value of the geomagnetic field. The AC amplitude $(50 \mu \mathrm{T})$ was set equal to the DC value and parallel to it as specified by Smith et al. [1987].

To increase the fluorescent intensity, 16-nm entrance and 4-nm exit slits were used, and the excitation beam onto the confluent sheet of cultured cells was defocused to illuminate the maximum number of cells and to minimize photobleaching. The illumination shutter (entrance shutter) was closed, except during actual exposures, again to minimize photobleaching. Photobleaching was found to be negligible.

\section{Cell Culture}

Four cell lines were used in the experiment. They were BALB/c3T3 cells (clone A31, American Type Culture Collection, Rockville, MD), L929 cells (NCTC clone 929, Flow Laboratories, McLean, VA), rat osteosarcoma osteoblastic cells (ROS clone 17/2.8; gift from Dr. Robert J. Majeska, University of Connecticut, Farmington), and V-79 Chinese hamster lung fibroblasts (gift from Dr. Fred Hutzel, Department of Radiation Oncology, Henry Ford Hospital, Detroit, MI). The BALB/c3T3 cells were plated and maintained in Dulbecco's modified minimum essential medium (DMEM; with $4.5 \mathrm{~g} / 1$ dextrose, Flow Laboratories, McLean, VA) plus $10 \%$ donor calf serum (Gibco Laboratories, Grand Island, NY). The L929 cells were plated in F- 12 (Gibco Laboratories, Grand Island, NY) with $10 \%$ fetal calf serum (FCS; Gibco, Grand Island, NY). They were subcultured weekly by a 1:10 split ratio and were maintained in the above complete medium or in a defined medium, F-12M. F-12M is a defined medium [Ham, 1965], which was obtained from Gibco Laboratories (Grand Island, NY) and has been useful in growing a number of continuous cell lines including L929 cells. This defined medium differs from F-12 only in the zinc sulfate concentration, $5 \times 10^{-7} \mathrm{M}$ in F-12M and $3 \times 10^{-6} \mathrm{M}$ in F-12. The L929-derived cell line in our laboratories will grow and maintain in F-12M alone, but at a slower rate than with F-12 plus $10 \%$ FCS. Furthermore, the cells have longer processes in F-12M than in F-12/FCS 10. The ROS cells were plated and maintained in F-12 medium plus 5\% FCS to which was added $28 \mathrm{mM}$ Hepes buffer, $\mathrm{CaCl}_{2}$ to raise the concentration to $1.1 \mathrm{mM}$, and glutamine to raise the concentration to $2.5 \mathrm{mM}$. The V-79 cells were plated in Eagle's basal medium with Hank's salts (Gibco Laboratories, Grand Island, NY) with 15\% FCS and maintained in minimum essential medium with Earle's salts (Gibco Laboratories, Grand Island, NY) with $10 \%$ FCS.

At the time of the experiments, the cells were plated on either rectangular coverslips or round glass cell chambers at a concentration of $10,000 \mathrm{cells} / \mathrm{cm}^{2}$, and placed in a $37{ }^{\circ} \mathrm{C}$ humid incubator in a $5 \% \mathrm{CO}_{2}$ atmosphere for $24-48 \mathrm{~h}$ until the cells were confluent as determined by phase-contrast microscopy. At confluency, BALB/ c3T3 cells exhibit contact inhibition, while L929 cells, V-79 cells, and ROS cells 
continue to grow and pile up as long as they have some contact with a substrate (plastic, collagen, glass).

The cells, after plating and growing to confluence on the coverslips, were loaded at $37{ }^{\circ} \mathrm{C}$ with the acetoxymethyl ester of fura2 (fura2AM, Molecular Probes, Inc., Eugene, OR). A variety of loading times, from $15 \mathrm{~min}$ to $3 \mathrm{~h}$, were tried with different concentrations of fura2AM: $0.3,1.5,3.0,15$, and $30 \mu \mathrm{M}$. At the higher values of 15 and $30 \mu \mathrm{M}$, the cells after 24 h showed signs of toxicity. As a result, a concentration of $3 \mu \mathrm{M}$ was routinely used. After loading and before mounting in the spectrometer, the cells were washed several times in a calcium-free buffered salt solution (BSS). This BSS consisted of $145 \mathrm{mM} \mathrm{NaCl}, 5 \mathrm{mM} \mathrm{KCl}, 1 \mathrm{mM} \mathrm{MgSO}$, $10 \mathrm{mM}$ Hepes [4-(2-hydroxethy)-1 piperazine-ethane sulfonic acid], $10 \mathrm{mM}$ glucose, pH 7.4 at $37{ }^{\circ} \mathrm{C}$ [Hallam et al., 1984]. The use of a balanced salt solution, which is calcium-free, and then the gradual addition of $\mathrm{Ca}^{2+}$ ions to physiologic concentrations is a routine procedure used by many investigators to investigate and demonstrate intracellular $\mathrm{Ca}^{2+}$ transients [Tang and Weinberg, 1986; Hallam et al., 1984]. While we did not look at the effect of $\mathrm{Ca}^{2+}$-free salt solutions on metabolic functions such as DNA or protein synthesis, we did observe the morphology of the cells by phase-contrast microscopy and the fura $2 \mathrm{AM}$ loading times, which were within the normal limits of morphology of healthy cells in culture medium, and the loading times of other fluorescent dyes. These BSS are nonnutritive and are formulated so that they are compatible with the vitality of the cells for at least a 3 -h period. Cell loading and hydrolyzation of the AM ester within the cells and the retention of fura2 in the cells were investigated in detail as described below.

\section{The Measurements}

Fura2AM loads into cells relatively quickly as judged by fluorescence microscopy. Within $15 \mathrm{~min}$ after beginning incubation, there is noticeable fluorescence and after $1 \mathrm{~h}$ at $37^{\circ} \mathrm{C}$ the intensity is high. That the fura2AM had indeed loaded into the cytoplasm of the cells was confirmed by measuring the intensity of the fluorescence emission as a function of wavelength $\left(E_{m}\right)$ for excitation wavelenghts $\left(E_{x}\right)$ of 340 and $380 \mathrm{~nm}$, removing and washing the coverslip containing the cells, and placing the coverslip and cells in a new cuvette with fresh buffer and remeasuring the spectra. At this point, the cell cytoplasm, but not the membranes or the extracellular medium, contained abundant fura 2 as demonstrated by fluorescent microscopy. The fura 2 complexes with free $\mathrm{Ca}^{2+}$ ions in the cytoplasm, but not with $\mathrm{Ca}^{2+}$ in other sites, such as those associated with plasma membrane enzymes. Cytosolic free $\mathrm{Ca}^{2+}$ is maintained at a relatively constant concentration $\left(\leq 10^{-7} \mathrm{M}\right)$ [Guyton, 1986]. This cytosolic concentration is maintained even when the cell is placed in a low or a high $\mathrm{Ca}^{2+}$ medium or when the cell is stimulated by a hormone (e.g., parathormone). Hormone stimulation or increased extracellular $\mathrm{Ca}^{2+}$ concentration is usually associated with a transient increase in cytosolic free $\mathrm{Ca}^{2+}$. The $\mathrm{Ca}^{2+}$ ions are then quickly transported into mitochondria or out of the cell by $\mathrm{Ca}^{2+}$ pump enzyme systems.

Before applying the EMF, the temporal stability of the loaded cell system was monitored by measuring the fluorescence emission intensity at $\mathrm{E}_{\mathrm{m}}=490 \mathrm{~nm}$ due to excitation at $E_{x}=340 \mathrm{~nm}$ as a function of time ("slow kinetics"). The fields were then applied at the calculated resonant frequency for calcium $(B=50 \mu \mathrm{T}$, $\mathrm{f}=38.15 \mathrm{~Hz}$ ) and the slow kinetics continued. Since the calcium ion may have an 
effective mass in the medium quite different from its free space mass, the applied frequency was varied considerably from the free space value of the resonant frequency. Other fixed frequencies were used, and the frequency was also slowly swept from 1 to $100 \mathrm{~Hz}$ (at approximately $10 \mathrm{~Hz} / \mathrm{min}$ ), maintaining constant amplitude as measured with an AC current meter, and also monitored on an oscilloscope. The slow kinetic scans were interrupted at intervals to record emission scans at excitations of 340 and $380 \mathrm{~nm}$. As shown by Tsien et al. [1985], changes in cytosolic $\mathrm{Ca}^{2+}$ concentration are reflected in changes in the ratio of the emission intensities for $E_{x}=340$ and 380 . The design of the SLM 8000C spectrofluorometer is well suited for such ratio measurements. The $340: 380$ ratio was measured with slow kinetics and also was calculated from the individual 340 and 380 spectra, with and without the applied fields.

In other measurements, $\mathrm{CaCl}_{2}$ (in $10-\mu$ l aliquots of $350 \mathrm{mM} \mathrm{CaCl}$ ) was added to the cuvette to increase the calcium concentration by $1.3 \mathrm{mM}$ with each aliquot, thus providing an excess of calcium in the external medium. $\left(1.3 \mathrm{mM} \mathrm{Ca}^{2+}\right.$ is the approximate physiologic concentration for plasma and extracellular fluid.) The fluorescent intensity was monitored, and after stabilization the EMF was applied. Following these measurements, the cells were removed, washed, and replaced in fresh medium as a check on the leakage of fura2 from the cells. Usually the last measurement on a given ensemble of cells was to determine their response to ionomycin and EGTA.

Ionomycin is a calcium ionophore, i.e., a small hydrophobic molecule that dissolves in the lipid membrane of a cell and mediates the passive (nonenzymatic) transport of $\mathrm{Ca}^{2+}$ ions down their electrochemical gradient [Ayers, 1986]. EGTA is a chelating agent, used routinely in this type of study after addition of $3 \mu \mathrm{M}$ ionomycin and $\mathrm{Ca}^{2+}$ to the external medium. EGTA chelates $\mathrm{Ca}^{2+}$ outside the cell and thus reduces the $\mathrm{Ca}^{2+}$ outside the cell, reversing the $\mathrm{Ca}^{2+}$ gradient and causing a transient low concentration of $\mathrm{Ca}^{2+}$ in the cytosol.

\section{RESULTS}

Measurements were made using the SLM-8000C spectrofluorometer on several ensembles of each of the three cell types: L929, BALB/c3T3, and ROS. V-79 cells were investigated only in the early measurements using the Aminco-Bowman spectrometer. In these early measurements, the sensitivity to changes in the fluorescent intensity was estimated to be $10 \%$. The application of the EMF did not measurably alter the observed fluorescent intensity.

The detailed investigation of the technique using the SLM-8000C was carried out with the L929 cell line. Typical emission spectra obtained for loaded L929 cells are shown in Figure 3. The increase in intensity with time of the fluorescence peak for $E_{x}=340 \mathrm{~nm}$ indicates hydrolyzation of the fura2AM ester and chelation of $\mathrm{Ca}^{2+}$. The shift in the peak position normally observed is essentially obscured in Figure 3 due to the wide 16-nm entrance and 4-nm exit slits. The particular L929 cell ensemble from which the data of Figures 3 and 4 were obtained was loaded in $3 \mathrm{ml}$ of Ca-free buffer containing $3 \mu \mathrm{M}$ fura2AM for $1.5 \mathrm{~h}$ before mounting in the spectrofluorometer. In Figure 4, the plots of emission intensity with time for $\mathrm{E}_{\mathrm{x}}=$ $340 \mathrm{~nm}$ (Fig. 4a) and $\mathrm{E}_{\mathrm{x}}=380 \mathrm{~nm}$ (Fig. 4b) were calculated from eight spectral plots, including those in Figure 3. Figure $4 c$, calculated from Figure $4 a, b$, is a plot 


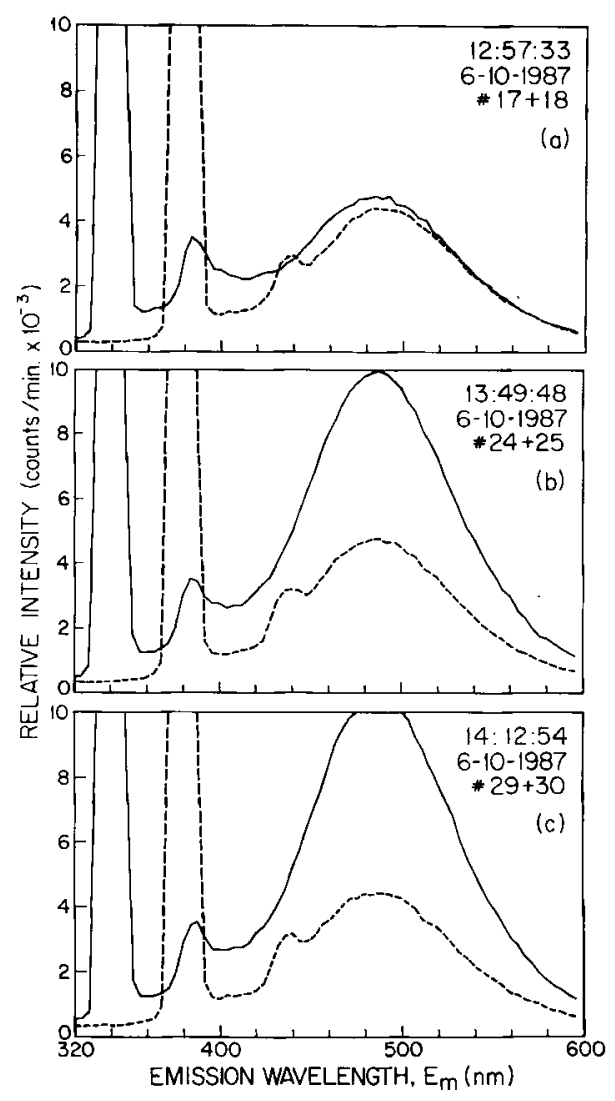

Fig. 3. Spectral emission from an ensemble of $L 929$ cells illustrating the chelation of $\mathrm{Ca}^{2+}$. Each graph contains two superimposed plots: one for excitation wavelength $E_{x}=340 \mathrm{~nm}$ (solid curve) and one for $E_{x}=380 \mathrm{~nm}$ (dashed curve). Entrance and exit slits were 16 and $4 \mathrm{~nm}$, respectively. The large peaks at the left, centered at $E_{m}=340$ and $380 \mathrm{~nm}$, are reflections by the sample holder of the incident radiation. The small peaks $\left(E_{m}=385\right.$ and $\left.440 \mathrm{~nm}\right)$ are artifacts, probably Raman scattering. The broad peaks, centered between $\mathrm{E}_{\mathrm{m}}=480$ and $500 \mathrm{~nm}$, indicate the relative fluorescence emission. The cells were loaded for $1.5 \mathrm{~h}$ in $3 \mu \mathrm{M}$ fura2AM in $3 \mathrm{ml}$ of Ca-free buffer, washed three times in buffer, and mounted in a cuvette containing $3 \mathrm{ml}$ of Ca-free buffer. a: Spectra immediately after mounting (clock time $=12: 57: 33$ ). b: The same cell ensemble 52 min later (clock time $=13: 49: 48$ ) after again washing the cells in Hallam's solution and mounting in a new cuvette with fresh buffer and $2.6 \mathrm{mM} \mathrm{CaCl} 2$. c: The same ensemble $23 \mathrm{~min}$ later (clock time $=14: 12: 54$ ) with $5.2 \mathrm{mM} \mathrm{CaCl}$. The temperature was maintained at $\mathrm{T}=37^{\circ} \mathrm{C}$.

of the 340:380 ratio as a function of time. The arrows indicate the times at which changes were made in the measurement conditions. The solid curves in Figure 4a,c are theoretical curves, exponential in form, fit by least squares to the experimental points. For curve $b$, the line is drawn just to connect the points. The hydrolyzation of the fura2AM and chelation of $\mathrm{Ca}^{2+}$ within the cells are essentially exponential with time, as is to be expected. It is to be noted that there is no significant change in curves $a-c$ when the EMF is applied.

Figure 5 is a slow kinetics scan of the fluorescence intensity at $\mathrm{E}_{\mathrm{m}}=490 \mathrm{~nm}$ for $\mathrm{E}_{\mathrm{x}}=340 \mathrm{~nm}$. The times of addition of $\mathrm{CaCl}_{2}$, EGTA, and Tris-base EGTA are shown. Ionomycin was added in the interval between $t=62.7$ and 104.7. 


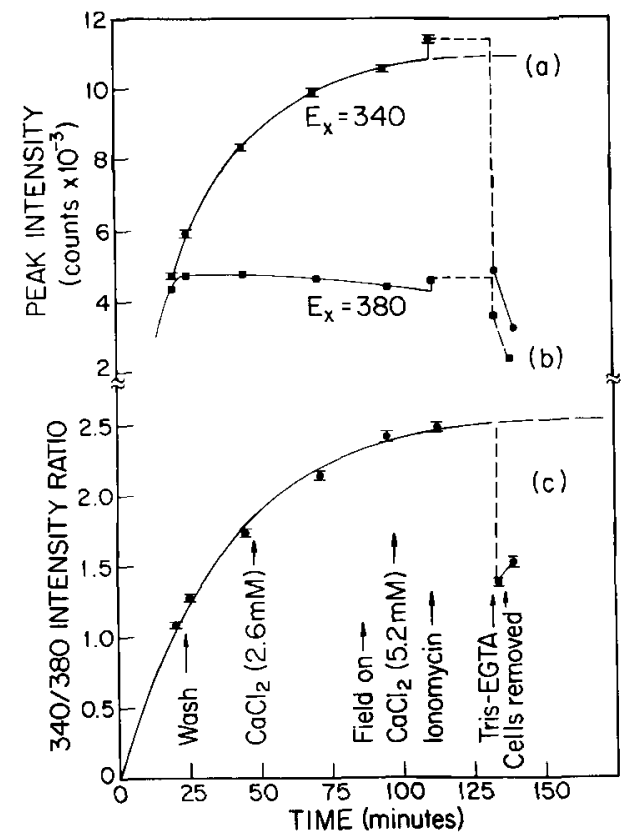

Fig. 4. a: The emission intensity at $E_{m}=490 \mathrm{~nm}$ for $E_{x}=340 \mathrm{~nm}$ as a function of time. The data points are taken from eight graphs, including the three of Figure 3 . The solid curve is given by $I=I_{s}$ $\left(1-\mathrm{e}^{-t / \tau}\right)$ fitted by least squares to the data, where $I_{s}=11,300, \tau=34.3 \mathrm{~min}$, and $\chi^{2}=23 \times 10^{3}$, where $\chi^{2}$ is the sum of the squares of the deviations of the data points from the calculated curve. Note particularly the increase in intensity following the addition of ionomycin and the decrease following the addition of Tris-EGTA. b: The emission intensity at $E_{m}=490 \mathrm{~nm}$ for $E_{\mathrm{k}}=380 \mathrm{~nm}$. The line is drawn just to connect the points. c: The $340: 380$ ratio for $E_{m}=490 \mathrm{~nm}$ calculated from the data points in a and b. The arrows indicate changes in the experimental conditions. The solid curve, again of the form $\mathrm{I}=$ $I_{s}\left(1-e^{-t / \tau}\right)$, when fitted by means of least squares yields $I_{s}=2.6, \tau=38.6 \mathrm{~min}$, and $\chi^{2}=2.9 \times 10^{-3}$. The time $t=0$ corresponds to $70 \mathrm{~min}$ after the start of loading. The exponential form and long time constant suggest a slow hydrolysis of the fura ester to the acid, or the diffusion of $\mathrm{Ca}^{2+}$ from internal stores (organelles) to the cytosol and not membrane transport, since washing at $1=5 \mathrm{~min}$, the addition of $\mathrm{CaCl}_{2}$ at $\mathrm{t}=48 \mathrm{~min}$, and the application of the EMF at $\mathrm{t}=86 \mathrm{~min}$ did not alter the rate of change of the emission intensity. The uncertainties associated with the data points are calculated from the statistics of counting only [Evans, 1955]. Note that while the intensities change significantly on the addition of ionomycin, the ratio did not change.

Figure 6 is a slow kinetics scan of the fluorescence intensity at $E_{m}=490 \mathrm{~nm}$ for $E_{x}=340 \mathrm{~nm}$. The time sequence is a-e, and the times at which changes were made in the conditions are marked by the large excursions. These fiducial marks were introduced by momentarily closing the entrance shutter. Note particularly that the addition of ionomycin $(10 \mu \mathrm{l}$ made the $3-\mathrm{ml}$ balanced salt solution $3 \mu \mathrm{M}$ with respect to $\mathrm{Ca}^{2+}$ ) did not significantly alter the ratio, but did alter the emission intensity for $E_{x}=340$ and 380 , as shown by Figure 4 .

Figure 7 is a slow kinetics scan of the fluorescence intensity at $E_{m}=490 \mathrm{~nm}$ for $E_{x}=340 \mathrm{~nm}$ for another ensemble of L929 cells taken on a different date and at $\mathrm{T}=36.7^{\circ} \mathrm{C}$. Again the fiducial marks indicate the times at which changes were made. The EMF was turned off and on, varied slowly and rapidly in frequency and amplitude, and the extracellular calcium concentration was varied. No measurable effect of the field was observed. 

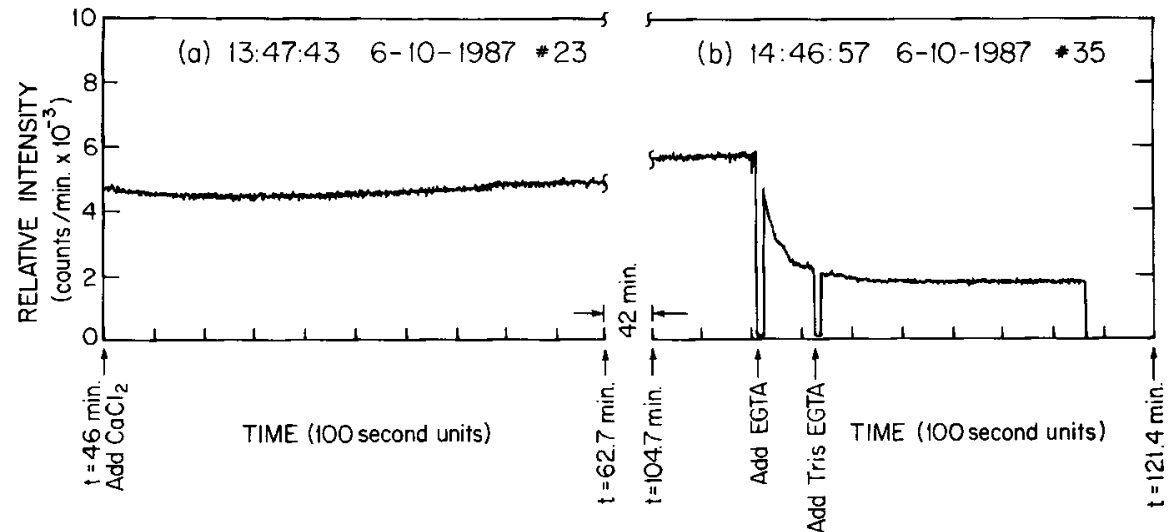

Fig. 5. Slow kinetics scan of the $E_{m}=490-\mathrm{nm}$ fluorescence intensity for $E_{x}=340 \mathrm{~nm}$. The times of addition of $\mathrm{CaCl}_{2}$, ionomycin, EGTA, and Tris-base EGTA are shown by arrows. The data of Figure 6 were taken in the time interval $\Delta t=42 \mathrm{~min}$ between $\mathbf{a}$ and $\mathbf{b}$ of this figure.

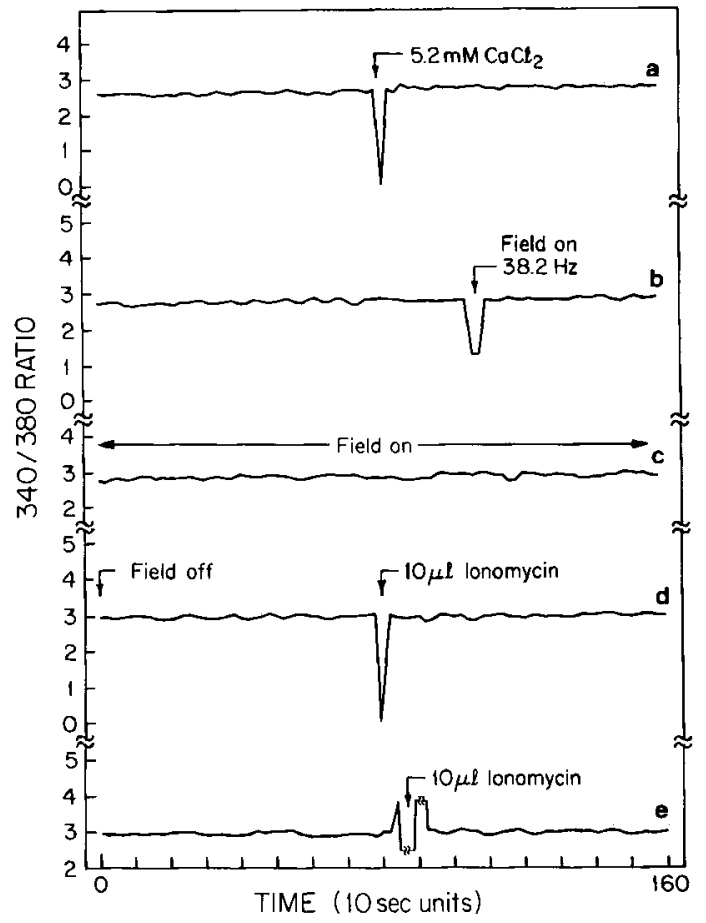

Fig. 6. Slow kinetics scan of the $340: 380$ ratio for $E_{m}=490 \mathrm{~nm}$ with changes as marked. The large excursions introduced by briefly closing the entrance shutter indicate the times at which changes were made. The total time interval of $30 \mathrm{~min}$ of the sequential curves a-e is contained in the $\Delta t=42-\mathrm{min}$ interval of Figure 5 . In e, the abrupt increase where 10- $\mu$ l ionomycin was added is an artifact introduced by the shutter and does not indicate a transient change in $\mathrm{Ca}^{2+}$ concentration.

Similar data for the BALB/c3T3 cells verified loading and hydrolyzation of the fura2AM, the 340:380 ratio increasing from 1.0 to 2.08 in approximately $30 \mathrm{~min}$ and remaining essentially constant over the hour in which measurements were made. No 

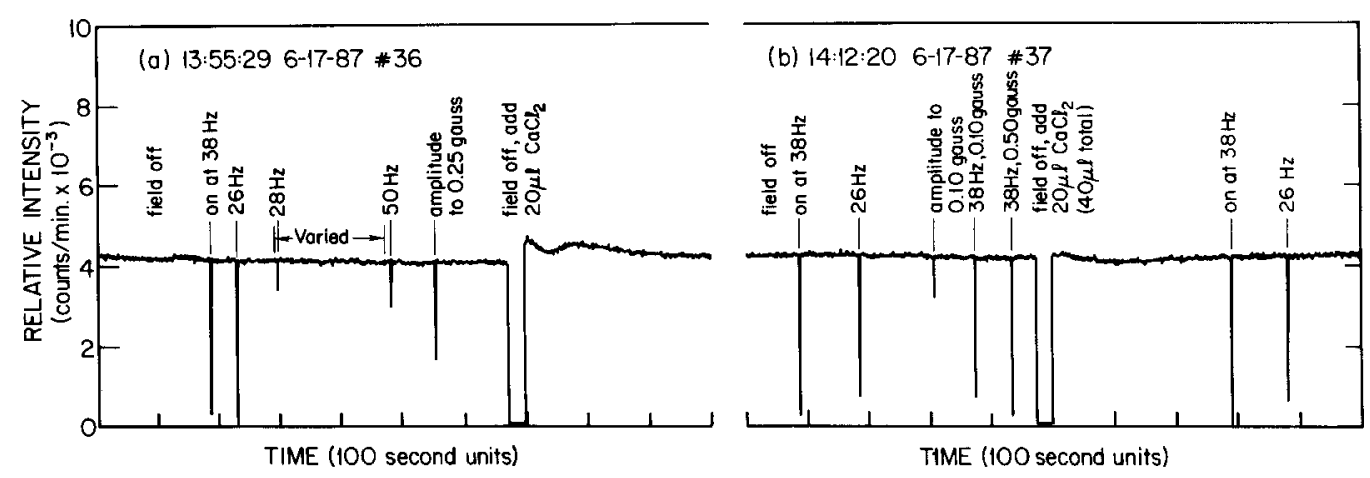

Fig. 7. Slow kinetics scan at $E_{m}=490 \mathrm{~nm}$ for $E_{x}=340 \mathrm{~nm}$ for an ensemble of L929 cells at $\mathrm{T}=$ $36.7^{\circ} \mathrm{C}$. The fiducial marks indicate the times at which changes were made. In a, the frequency was varied slowly and steadily from 28 to $50 \mathrm{~Hz}$ between $\mathrm{t}=300$ and $480 \mathrm{~min}$. At $\mathrm{t}=550 \mathrm{~min}$, the amplitude of the AC field was decreased from 50 to $25 \mu \mathrm{T}$. The field was turned off at $\mathrm{t}=670 \mathrm{~min}$ and $20 \mu \mathrm{CaCl} \mathrm{Ca}_{2}$ was added to the cuvette. Curve $b$ is a continuation of a with changes as noted in the figure. No measurable effect of the field is observed.

change in emission intensity at $\mathrm{E}_{\mathrm{m}}=490 \mathrm{~nm}$ was observed with the EMF on and with it off. The time intervals between changes in the applied EMF were similar to those for the L929 cells. They were necessarily arbitrary since there is limited information on the response time to be expected. (See Discussion for the comments on response time and the sensitivity of measurement.)

The same measurements for the ROS cells loaded for $1 \mathrm{~h}$ indicate that the $340: 380$ ratio increases to 1.55 in $19 \mathrm{~min}$, and again no change in the $\mathrm{E}_{\mathrm{m}}=490-\mathrm{nm}$ emission intensity was observed in a slow kinetics scan with the EMF on and off.

There was no measurable autofluorescence for any of the cell lines measured as determined with either the fluorescence microscope or the spectrofluorometer (Fig. 8).

Thus, no evidence was found for transient change in cytosolic calcium concentration due to an applied EMF of the amplitudes and frequencies used in these measurements for the four cell lines studied. Thus, by the present method of analysis, no evidence was gained for transmembrane transport (influx or efflux) or for release of mitochondrial calcium. It should be emphasized that the cells used in these experiments are continuous cell lines, not embryonic. Of the three cell typesBALB/c3T3, L929, and ROS_only the ROS cells (a differentiated osteoblast cell line from a rat bone tumor) display a galvanotropic response at an electric field of 4.5 volts $/ \mathrm{cm}$. [Parkinson and Hanks, 1986], a response that appears to be characteristic of some primary embryonic cell lines. Thus, it is possible that primary embryonic (neural crest and somitic fibroblast) cells and differentiated osteoblasts might display a cyclotron-resonance response. Measurements on these cell lines are being considered.

\section{DISCUSSION}

A variety of studies with different kinds of cells including embryonic neural crest cells [Cooper and Keller, 1984; Stump and Robinson, 1983], embryonic somitic fibroblasts [Erickson and Nuccitelli, 1984; Parkinson and Hanks, 1986], fish 


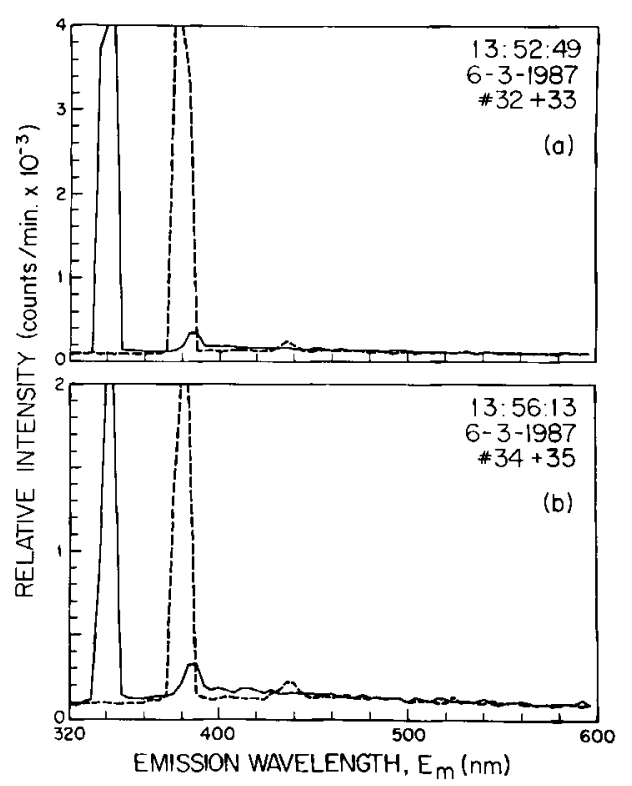

Fig. 8. a: Emission spectra for $E_{x}=340$ and $380 \mathrm{~nm}$ for $L 929$ cells after "loading" cells with fura2 acid for $2.5 \mathrm{~h}$, then washing to remove the fura 2 acid from the external medium. b: Adding $\mathrm{CaCl}_{2}$ to the fura2-free external medium did not change the fluorescent intensity. It is concluded that fura 2 acid does not load into the cells. There is no significant autofluorescence of the cells, coverslips, and medium.

keratinocytes [Cooper and Schliwa, 1986], osteoclast and osteoblast cell clones [Ferrier et al., 1986], and several other cell types [Robinson, 1985] have shown that electric fields with potentials in the range of $0.1-100 \mathrm{mV} / \mathrm{mm}$ have the ability to influence the orientation of these cells (galvanotropism) as well as their movement (galvanotaxis). It is the opinion of most of these investigators that this orientation and movement is related to the enhanced influx of cations, particularly $\mathrm{Ca}^{2+}$. Evidence of the role of calcium in these phenomena include the facts that small changes (micromolar concentrations) of extracellular ionic calcium are capable of causing retraction of cell processes of neural crest cells [Cooper and Keller, 1984], and that calcium channel blockers reversibly inhibit formation of lamellipods and cell locomotion of fish keratinocytes [Cooper and Schliwa, 1986]. Finally, several fluorescing calcium chelating agents that are transported across the plasma membrane to the cytosol have been used to investigate transient $\mathrm{Ca}^{2+}$ changes in the cytosol when cells are subjected to a variety of stimuli such as vasopressin stimulation [Tang and Weinberg, 1986], thrombin and platelet-activating factor [Tsien et al., 1985; Hallam et al., 1984], epidermal growth factor [Pandiella et al., 1987], and many others. These studies suggested that if the physiological processes are somehow mediated by $\mathrm{Ca}^{2+}$ either by transport or "flux," or by release of the $\mathrm{Ca}^{2+}$ from mitochondria, and if in fact a resonant EMF enhances the process, then the use of the improved fluorescent calcium chelating agent fura 2 should be a good method for demonstrating the effect.

The correct interpretation of the experimental results requires that a number of questions be answered about the technique. Because the cell membrane is impermeant to the fura 2 acid (see Fig. 8), it is necessary to "load" the cells with the acetoxy- 
methyl ester of fura2 (fura2AM). Once ingested into the cytoplasm, the ester must be hydrolyzed to the acid by the cytosolic esterases before it will chelate calcium ions. This can be a slow process as shown by the plots in Figures 3 and 4 .

A separate test of cell loading was made using fluorescent microscopy. L929 cells were grown to near confluence in Ham's F12M at $37^{\circ} \mathrm{C}$ in plastic culture dishes (Falcon \#3002 dishes; Oxnard, CA; $60 \times 15 \mathrm{~mm}$ ). After washing in the calcium-free balanced salt solution [Hallam et al., 1984], $3 \mathrm{ml}$ of this solution containing $3 \mu \mathrm{M}$ fura2 $\mathrm{AM}$ was placed in the dish and incubated at $37^{\circ} \mathrm{C}$ for $30 \mathrm{~min}$, by which time the cells showed strong fluorescence. The cells were again washed in the calcium-free balanced salt solution and incubated in this same solution for varying periods of time. A Leitz Diavert (Rockleigh, NJ) inverted microscope, equipped with Ploemopak (E. Leitz, Rockleigh, NJ) 2.2 incident fluorescent illuminator and relatively broad-band filter blocks (270 - to 380-nm excitation range), was used to observe the fluorescence. The microscope was not equipped with a photon detector, hence estimates of the fluorescent intensity were made by eye, a notoriously poor absolute intensity measuring device. It could be concluded from these qualitative measurements, however, that at $37^{\circ} \mathrm{C}$ the fura2AM loaded into the cytoplasm in about $30 \mathrm{~min}$. There was no evidence that the cell membrane or the glycocalyx was preferentially loaded with fura2. Only the cytoplasm was fluorescent after loading. These results are consistent with those made with the spectrofluorometer.

Leaking of fura 2 from the cells can be significant, particularly at $\mathrm{T}=37^{\circ} \mathrm{C}$. The data of Figure $4 \mathrm{c}$ indicate that on a short time scale (at $t=25 \mathrm{~min}$ ), the leakage was small since on washing and adding fresh medium the fluorescence intensity was not reduced but continued to rise exponentially. However, over a 3-h period, the leakage was $41 \%$. This was determined from the decrease in fluorescence intensity after removing the coverslip containing the cells, washing in buffer, and replacing in the spectrof luorometer in a new cuvette with fresh buffer. Furthermore, loaded cells, incubated for $24 \mathrm{~h}$ at $37^{\circ} \mathrm{C}$, exhibited no fluorescence, indicating that most or all the fura 2 had "leaked" out, probably by exocytosis.

Calcium is thought to be one of the "universal" second messengers signaling plasma membrane stimulation. In hormonal stimulations where $\mathrm{Ca}^{2+}$ influx is observed, an increase in cytosolic $\mathrm{Ca}^{2+}$ is transient even during a sustained cellular response [Rasmussen and Barrett, 1984]. Although $\mathrm{Ca}^{2+}$ influx may be sustained at four to five times the basal rate, net $\mathrm{Ca}^{2+}$ accumulation does not occur. It is hypothesized that cytosolic $\mathrm{Ca}^{2+}$ levels are controlled by increased $\mathrm{Ca}^{2+}$ efflux, by binding to cellular proteins, and by $\mathrm{Ca}^{2+}$ storage in other cellular compartments (e.g., mitochondria). If calcium is available in the external medium, the addition of ionomycin should increase the fluorescence intensity. EGTA, on the other hand, is a $\mathrm{Ca}^{2+}$ chelator and takes calcium from the fura 2 when the cells have been treated with ionomycin. An increase in cytosolic $\mathrm{Ca}^{2+}$ was observed after treatment of the cells with ionomycin, and an efflux of $\mathrm{Ca}^{2+}$ was induced by EGTA. Thus, the addition of EGTA should transiently reduce the relative fluorescent intensities and the 340:380 ratio. This is illustrated by the data of Figure 4 . If the resonant EMF had enhanced the $\mathrm{Ca}^{2+}$ transport, a change in intensity should have been observed in Figure 4 as well as in Figures 6 and 7. This was not observed under the experimental conditions described here, hence we conclude that the EMFs, both "resonant"' and nonresonant, did not enhance $\mathrm{Ca}^{2+}$ transport in either direction across the plasma membrane or from the organelles. 
A question for which the answer has not been determined is the value of the time constant associated with enhanced calcium transport, if it exists, due to a cyclotron resonance. From diffusion rates and membrane transport data it should be short, of the order of a few seconds [Halm and Dawson, 1984].

A very rough estimate of the time constant and the sensitivity of the measurements to changes in cytosolic $\mathrm{Ca}^{2+}$ concentration $\left[\mathrm{Ca}^{2+}\right]_{\mathrm{c}}$ can be made on the following basis: Assuming the normal cytosolic concentration to be $100-200 \mathrm{nM}$, as predicted by the Nernst equation [also Rasmussen and Barrett, 1984], then in the volume of a cell, taken as $4 \times 10^{-16} \mathrm{~m}^{3}$, there would be of the order of $4 \times 10^{4}$ $\mathrm{Ca}^{2+}$ ions. The number of calcium channels per cell is not known, but based on the number of $\mathrm{Na}$ channels [Darnell et al., 1986], 400 is a reasonable number. Thus, to reduce the cytosolic $\mathrm{Ca}^{2+}$ concentration by $200 \mathrm{nM}$ requires that each channel transport on the average 100 ions. Calculations based on nuclear magnetic resonance (NMR)-derived rate constants for gramicidin channels [Urry et al., 1980] suggest a conduction of $10^{7}$ ions per second per channel for a $1 \mathrm{M}$ external to $10^{-7} \mathrm{M}$ internal concentration gradient. Thus, for $10^{-3} \mathrm{M}$ external to $10^{-7} \mathrm{M}$ internal concentration, a conduction of $10^{6}$ ions per second per channel would seem to be a conservative estimate. This leads to a transient time constant of the order of milliseconds, as is observed via patch clamp techniques.

A change in fluorescent intensity of the order of $3 \%$ would be detectable in the data of Figure 5. The addition of EGTA (Fig. 5) results in a factor of 3.1 decrease in intensity, a decrease due to reduction of $\left[\mathrm{Ca}^{2+}\right]_{c}$. Again for a normal cytosolic concentration of $200 \mathrm{nM}$, then a change of $2 \mathrm{nM}$ concentration is just detectable, or $\left[\Delta \mathrm{Ca}^{2+}\right]_{\mathrm{c}} /\left[\mathrm{Ca}^{2+}\right]_{\mathrm{c}}=1 \%$. This requires on the average of only one ion per second per channel, a remarkably low number. At the other extreme, say only one calcium channel per cell, a transport of only 400 ions per second per channel would be required. This excellent sensitivity is due to the properties of fura2, and represents a significant improvement over the ionophore quin 2 . These conclusions are consistent with the calibration of the fluorescence of fura 2 by Grynkiewicz et al. [1985]. It might be noted that Bawin and Adey [1976] report an 11-15\% effect at the "window." Blackman et al. [1985] report a 15-20\% effect, while McLeod et al. [1987] report an increase in the ratio of ${ }^{45} \mathrm{Ca}$ uptake of a factor of 3 at resonance.

As an extension of these measurements, a microtechnique that promises to be a sensitive indicator of $\mathrm{Ca}^{2+}$ efflux from the cytoplasm is being developed. The basis of the technique is that fura 2 acid does not enter the cell. If the volume of the medium external to the cells is small and contains fura2 acid, then the small amounts of $\mathrm{Ca}^{2+}$ moving out the cells will shift the wavelength and intensity of fluorescence emission.

\section{CONCLUSIONS}

On the basis of the data described here, there is no evidence that the EMFs used in these measurements have any effect, sustained or transient, on calcium transport across the cell membrane or from internal calcium stores. Thus, there is no indication from these data of a "cyclotron resonance" effect. This does not rule out that such an effect may exist for embryonic cells and tissue from the central nervous system such as those used by Bawin and Adey [1976] or by Blackman et al. [1985]. 


\section{ACKNOWLEDGMENTS}

It is with pleasure that we acknowledge the help of Dr. Joel Weinberg, Department of Nephrology, in introducing us to the technique used in automatic intracellular calcium measurements. We also acknowledge Dr. W.J. O'Brien of the Dental School for permitting us the use of his laboratory and the Aminco-Bowman spectrometer. By far the more extensive measurements reported here were made using the SLM8000C spectrofluorometer in the laboratory of Dr. Daniel Axelrod, Department of Physics and Biophysics Research Division of the Institute of Science and Technology. His assistance is greatly appreciated. We also wish to thank Dr. Robert Majeska, University of Connecticut, Farmington, for supplying us with the ROS cells and Dr. Fred Hutzel, Henry Ford Hospital, Detroit, MI, for supplying the V-79 cells. This research was sponsored in part by the National Institute of Dental Research (Sponsor No. 2-S07-RR05321-25).

\section{REFERENCES}

Adey WR (1974): The influences of impressed electrical fields at EEG frequencies on brain and behavior. In Altshuler and Burch (eds): "Behavior and Brain Electrical Activity." New York: Plenum Press.

Ayers CJ (1986): "Molecular Cell Biology." Reading, MA: Addison-Wesley, p 166.

Bawin SM, Adey WR (1976): Sensitivity of calcium binding in cerebral tissue to weak environmental electrical fields oscillating at low frequency. Proc Natl Acad Sci USA 73:1999-2003.

Bawin SM, Kaczmarek LK, Adey WR (1975): Effects of modulated VMF fields on the central nervous system. Ann NY Acad Sci 247:74-81.

Blackman CF (1985): Biological influences of low frequency sinusoidal electromagnetic signals alone and superimposed on RF carrier waves. In Chiabrera A, Nicolini C, Schwann HP (eds): "Interactions Between Electromagnetic Fields and Cells."' London: Plenum Press, pp 521-535.

Blackman CF, Benane SG, Kinney LS, House DE, Joines WT (1982): Effects of ELF fields on calcium-ion efflux from brain tissue in vitro. Radiat Res 92:510-520.

Blackman CF, Benane SG, Rabinowitz JR, House DE, Joines WT (1985): A role for the magnetic field in the radiation-induced efflux of calcium ions from brain tissue in vitro. Bioelectromagnetics 6:327-337.

Chiabrera A, Bianco B, Caratozzolo F, Giannetti G, Grattorola M, Viviani R (1985): Electric and magnetic field effects on ligand bonding to the cell membrane. In Chiabrera A, Nicolini C, Schwann HP (eds): "Interactions Between Electromagnetic Fields and Cells." London: Plenum Press, pp 253-280.

Conti P, Gigante GE, Cifone MG, Alesse E, Ianni G, Reale M, Angeletti PU (1983): Reduced mitogenic stimulation of human lymphocytes by extremely low frequency electromagnetic fields. FEBS Lett 162:156-160.

Cooper MS, Keller RE (1984): Perpendicular orientation and directional migration of amphibian neural crest cells in DC electrical fields. Proc Natl Acad Sci USA 81:160-164.

Cooper MS, Schliwa M (1986): Motility of cultured fish epidermal cells in the presence and absence of direct current electric fields. J Cell Biol 102:1384-1399.

Darnell J, Lodish H, Baltimore D (1986): “Molecular Cell Biology.” New York: Scientific American, $\mathrm{p} 732$.

Delgado JMR, Leal J, Monteazudo JL, Gracia MG (1982): Embryological changes induced by weak extremely low frequency electromagnetic fields. J Anat 134:533-551.

Erickson CA, Nuccitelli R (1984): Embryonic fibroblast motility and orientation can be influenced by physiological electric fields. J Cell Biol 98:296-307.

Evans RD (1955): “The Atomic Nucleus.” New York: McGraw-Hill, p 746.

Ferrier J, Ross SM, Kanehisa J, Aubin JE (1986): Osteoclast and osteoblasts migrate in opposite directions in response to a constant electrical field. J Cell Physiol. 129:283-288.

Grynkiewicz G, Poenie M, Tsien RY (1985): A new generation of $\mathrm{Ca}^{2+}$ indicators with greatly improved fluorescence properties. J Biol Chem 260:3440-3450. 
Guyton AC (1986): "Textbook of Medical Physiology." 7th Ed. Philadelphia: W.B. Saunders, p 149. Hallam TJ, Sanchez A, Rink TJ (1984): Stimulus-response coupling in human platelets. Biochem J 218:819-827.

Halm DR, Dawson DC (1984): Potassium transport by turtle colon: Active secretion and active absorption, Am J Physiol 246:C315-C322.

Ham RG (1965): Clonal growth of mammalian cells in a chemically defined synthetic medium. Proc Natl Acad Sci USA 53:288-293.

Liboff AR (1985): Cyclotron resonances in membrane transport: In Chiabrera A, Nicolini C, Schwan HP (eds): "Interactions Between Electromagnetic Fields and Cells." London: Plenum Press, pp 281-296.

McLeod BR, Smith SD, Cooksey KE, Liboff AR (1987): Ion cyclotron resonance frequencies enhance $\mathrm{Ca}^{++}$-dependent motility in diatoms. J Bioelectr 6:1-12.

Pandiella A, Malgaroli A, Meldolesi J, Vicentini LM (1987): EGF raises cytosolic $\mathrm{Ca}^{2+}$ in A431 and Swiss 3T3 cells by a dual mechanism. Exp Cell Res 170:175-185.

Parkinson WC, Hanks CT (1986): Response of primary and transformed cells to electromagnetic fields. Nuccitelli R (ed): In “Ionic Currents and Development." New York: Alan R. Liss, pp 329-336.

Rasmussen H, Barrett PQ (1984): Calcium messenger system: An integrated view. Physiol Rev 64:938-984

Robinson KR (1985): The response of cells to electrical fields: A review. J Cell Biol 101:2023-2027.

Smith SD, McLeod BR, Liboff AR, Cooksey K (1987): Calcium cyclotron resonance and diatom motility. Bioelectromagnetics 8:215-227.

Stump RF, Robinson KR (1983): Xenopus neural crest cell migration in an applied electrical field. J Cell Biol 97:1226-1233.

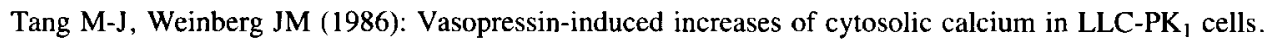
Am J Physiol 251:F1090-F1095.

Tsien RY, Rink TJ, Poenie M (1985): Measurement of cytosolic free $\mathrm{Ca}^{2+}$ in individual small cells using fluorescence microscopy with dual excitation wavelengths. Cell Calcium 6:145-157.

Urry DW, Venkatachalam CM, Spisni A, Läuger P, Khaled MA (1980): Rate theory calculations of gramicidin single-channel currents using NMR-derived rate constants. Proc Natl Acad Sci USA 77:2028-2032 